\title{
Heat inactivation of the extracellular proteinase from Pseudomonas fluorescens 22F : inactivation during heating up and cooling periods
}

\author{
BY ERIX P. SCHOKKER AND MARTINUS A. J. S. VAN BOEKEL \\ Wageningen Agricultural University, Department of Food Technology and Nutritional \\ Sciences, Division of Food Science, PO Box 8129, NL-6\%00 EV Wageningen, \\ The Netherlands
}

(Received 17 August 1998 and accepted for publication 20 January 1999)

We have reported previously on the kinetics of thermal inactivation at $80-120{ }^{\circ} \mathrm{C}$ of the extracellular proteinase from Pseudomonas fluorescens 22F (Schokker \& van Boekel, 1997, 1999b). During these studies, we noted some inactivation during the heating up and cooling periods, but allowed for this by calculating the residual activity as a fraction of the activity after the heating up period of $2 \mathrm{~min}$ followed by cooling to $0{ }^{\circ} \mathrm{C}$. However, it may be of interest to evaluate the extent of inactivation during these heating up and cooling periods. If the temperature dependence of the reaction rate behaves according to Eyring's theory, inactivation would, of course, be slower than at the final heating temperature. However, during the heating and cooling of the enzyme solution, the temperature also passes the region in which autoproteolysis occurs (Schokker \& van Boekel, 1998a). Prolonged residence time in the critical zone for autoproteolysis may cause increased inactivation, as has been demonstrated in electrophoresis experiments for proteinases from other $P s$. fluorescens strains (Barach \& Adams, 1977; Richardson, 1981; Diermayr et al. 1987). Consequently, the inactivation during the first few minutes would be dependent on factors influencing both autoproteolytic and thermal inactivation.

In most of our heating experiments (Schokker \& van Boekel, 1997, 1999b), inactivation during heating up was relatively rapid compared with inactivation at the final heating temperature, leading to a biphasic inactivation curve. This was also found for proteinases from many other Ps. fluorescens strains. In some studies the inactivation during heating up was not taken into account when analysing the kinetics of thermal inactivation (Patel et al. 1983; Yan et al. 1985; Fairbairn \& Law, 1986), which led to misinterpretation of the mechanism or the kinetic values. Others explained the biphasic inactivation curve by autoproteolysis (Barach \& Adams, 1977; Richardson, 1981; Stepaniak \& Fox, 1983; Kroll \& Klostermeyer, 1984; Diermayr et al. 1987), or stabilization by $\mathrm{Ca}^{2+}$ of a small portion of the proteinase to heat inactivation (Stepaniak \& Fox, 1983; Azcona et al. 1988).

In this paper we discuss the influence of protein, enzyme purification and $\mathrm{Ca}^{2+}$ activity on inactivation during the heating up and cooling periods. The aim of this study was to determine, using kinetic modelling, whether the inactivation during heating up and cooling periods could be explained by autoproteolysis and thermal inactivation, or whether other mechanisms are involved in the strong initial inactivation. 


\section{EXPERIMENTAL}

Inactivation measurements were taken from the experiments described in Schokker \& van Boekel $(1999 b)$. In these experiments the relative activity of unheated samples was compared with that of samples heated for 2 min (i.e. the heating up time). These values provide information about the amount of proteinase inactivated during the heating up and cooling periods. In the experiments the enzyme solutions $(2 \cdot 1 \mathrm{ml})$ were heated in stainless steel tubes $(7 \times 120 \mathrm{~mm})$, which were rotated in a thermostatted glycerol bath. The tubes were then immediately cooled in ice-water. Assuming that the temperature was uniform throughout the tubes, the following equation can be used to describe the profile of temperature increase and decrease (Hiddink, 1975).

$$
V \rho c_{\mathrm{p}} \frac{\mathrm{d} T}{\mathrm{~d} t}=\Phi A\left(T_{\mathrm{w}}-T\right),
$$

where $V$ is the volume of the liquid to be heated $\left(2 \cdot 1 \times 10^{-6} \mathrm{~m}^{3}\right), \rho$ the density of the liquid $\left(1025 \mathrm{~kg} \mathrm{~m}^{-3}\right), c_{\mathrm{p}}$ the heat capacity of the liquid $\left(3950 \mathrm{~J} \mathrm{~kg}^{-1} \mathrm{~K}^{-1}\right), \Phi$ the overall heat transfer coefficient $\left(\mathrm{W} \mathrm{m}^{-2} \mathrm{~K}^{-1}\right), A$ the heating surface area $\left(2.6 \times 10^{-3}\right.$ $\left.\mathrm{m}^{2}\right)$ and $T_{\mathrm{w}}$ the temperature of the tube wall $(\mathrm{K})$. Integration gives

$$
\frac{T_{\mathrm{w}}-T}{T_{\mathrm{w}}-T_{0}}=\exp \left(-\frac{\Phi A t}{V \rho c_{\mathrm{p}}}\right),
$$

where

$$
\frac{1}{\Phi}=\frac{1}{\alpha_{\text {glycerol }}}+\frac{d_{\mathrm{w}}}{\lambda_{\mathrm{w}}}+\frac{1}{\alpha_{\text {enzyme solution }}},
$$

and where $\alpha$ is the heat transfer coefficient $\left(\mathrm{W} \mathrm{m}^{-2} \mathrm{~K}^{-1}\right), d_{w}$ the thickness of the tube wall $\left(1 \cdot 0 \times 10^{-3} \mathrm{~m}\right), \lambda_{\mathrm{w}}$ the heat conductivity of the tube wall $\left(50 \mathrm{~W} \mathrm{~m}^{-1} \mathrm{~K}^{-1}\right)$ and $t$ the heating time. Because $\alpha_{\text {glycerol }}$ and $\alpha_{\text {enzyme solution }}$ were unknown, $\Phi$ had to be estimated, such that the calculated temperatures fitted the measured temperature profiles. When the tubes were not rotating, $\Phi$ was estimated at $120 \mathrm{~W} \mathrm{~m}^{-2} \mathrm{~K}^{-1}$. When the tubes were rotating, $\Phi$ would have been larger and the temperature would change faster.

\section{RESULTS AND DISCUSSION}

The extent of inactivation during heating up and cooling the enzyme solution, taken from experiments described in Schokker \& van Boekel (1999b), is given in Table 1. In most cases this inactivation was relatively rapid compared with that at the final heating temperature.

The extent of inactivation of the proteinase during heating up was strongly affected by the composition of the solution. The presence of $15 \mathrm{~g}$ sodium caseinate/l reduced the inactivation. This stabilizing effect of proteins against inactivation during heating up was also found by Barach et al. (1976), Richardson (1981) and Yan et al. (1985). Assuming that the rapid inactivation during heating up is caused by autoproteolysis, the presence of other proteins would be expected to have an influence, as they would reduce the rate of autoproteolysis (Barach et al. 1978; Stepaniak \& Fox, 1983; Schokker \& van Boekel, 1998b). Other explanations for the protective action of proteins could be that they stabilize a critical conformation near the active site by an enzyme-substrate complex or facilitate refolding (Mihalyi, 1972). 
Table 1. Relative activity of the extracellular proteinase from Pseudomonas fluorescens $22 F$ after 2 min heating up time compared with that of the unheated enzyme solution†

(Values are means \pm SD for $n=3$ )

\begin{tabular}{|c|c|c|c|c|c|}
\hline \multirow{2}{*}{$\begin{array}{c}\text { Temperature, } \\
{ }^{\circ} \mathrm{C}\end{array}$} & \multicolumn{4}{|c|}{ Unpurified enzyme in } & \multirow{2}{*}{$\begin{array}{l}\text { Purified } \\
\text { enzyme in } \\
\text { solution } \mathrm{E}\end{array}$} \\
\hline & Solution A & Solution B & Solution C & Solution D & \\
\hline 80 & $0 \cdot 62 \pm 0 \cdot 09$ & $0 \cdot 98 \pm 0 \cdot 03$ & $0 \cdot 66 \pm 0 \cdot 02$ & - & $0 \cdot 75 \pm 0 \cdot 14$ \\
\hline 90 & - & - & $0 \cdot 80 \pm 0.11$ & $0.52 \pm 0.06$ & $0 \cdot 74 \pm 0.09$ \\
\hline 95 & $0 \cdot 74 \pm 0 \cdot 10$ & $0 \cdot 92 \pm 0 \cdot 08$ & - & - & - \\
\hline 100 & - & - & $0 \cdot 77 \pm 0 \cdot 09$ & $0 \cdot 36 \pm 0 \cdot 03$ & $0 \cdot 66 \pm 0 \cdot 32$ \\
\hline 105 & $0 \cdot 73 \pm 0 \cdot 02$ & $0 \cdot 90 \pm 0 \cdot 06$ & - & 一 & - \\
\hline 110 & - & - & $0 \cdot 79 \pm 0 \cdot 06$ & $0.57 \pm 0 \cdot 01$ & $0 \cdot 63 \pm 0 \cdot 18$ \\
\hline 120 & $0 \cdot 67 \pm 0 \cdot 03$ & $0 \cdot 72 \pm 0 \cdot 07$ & $0 \cdot 68 \pm 0.08$ & $0 \cdot 60 \pm 0 \cdot 08$ & $0.51 \pm 0.09$ \\
\hline
\end{tabular}

$\dagger$ Solutions were A, $0 \cdot 2 \mathrm{M}$-Tris-maleate buffer with $2 \mathrm{~mm}-\mathrm{CaCl}_{2} ; \mathrm{B}, 0 \cdot 2 \mathrm{M}$-Tris-maleate buffer with 2 mu$\mathrm{CaCl}_{2}$ and $15 \mathrm{~g}$ sodium caseinate/l; C, $0 \cdot 2 \mathrm{M}$-Tris-maleate buffer with $20 \mathrm{~mm}-\mathrm{CaCl}_{2} ; \mathrm{D}, 0 \cdot 2 \mathrm{M}$-Tris-maleate buffer with $0 \cdot 5$ mм-EDTA; E, $0 \cdot 2$ м-Tris-maleate buffer alone ( $\mathrm{pH} 7 \cdot 4$ in all cases). For details of these solutions, see Schokker (1997).

The $\mathrm{Ca}^{2+}$ activity also appeared to have a strong influence on the inactivation during heating up. Reduction of the $\mathrm{Ca}^{2+}$ activity by adding EDTA increased the initial inactivation of the proteinase (Table 1). This difference was unexpected, because the rates of autoproteolysis and thermal inactivation are not affected by $\mathrm{Ca}^{2+}$ activity (Schokker \& van Boekel, 1999a,b). A mechanism for the protective effect of calcium was proposed by Barach \& Adams (1977). Most of the extracellular proteinases from $P s$. fluorescens strains are metalloproteinases, containing a zinc ion at the active site. In addition to this catalytic metal ion, $\mathrm{Ca}^{2+}$ ions are present as structural elements, forming salt bridges. These salt bridges are thought to be important for regeneration of the native conformation of the proteinase, rather than maintenance of native structure during heating. $\mathrm{Ca}^{2+}$, as well as other divalent metal ions, would stabilize part of the native structure near the active site of the proteinase, allowing rapid and accurate enzyme renaturation. Possibly partial unfolding by heat is necessary for removal of the divalent metal ions by EDTA. Another mechanism for initial inactivation in the presence of EDTA was found for thermolysin, the extracellular metalloproteinase from Bacillus thermoproteolyticus (Vita et al. 1985; Fassina et al. 1986; Fontana, 1988). In the presence of EDTA, susceptibility to autoproteolysis of the native thermolysin molecule is increased, and the molecule can be hydrolysed into three peptide chains. These parts do not separate, but form a complex with a relative specific activity lower than that of the native molecule. Upon heating, the complex falls apart, resulting in irreversible inactivation.

The increased inactivation during heating up and cooling was more pronounced when the heating temperature was relatively low $\left(80-90^{\circ} \mathrm{C}\right)$, except when sodium caseinate was present in the solution. Assuming that the increased inactivation was caused by autoproteolysis, this would be expected, since the time necessary to pass through the critical temperature range for autoproteolysis was relatively long (eqns $1-3)$.

To investigate whether or not autoproteolysis was the sole cause of the relatively rapid inactivation during heating up and cooling, we estimated the loss of proteolytic activity by autoproteolysis and thermal inactivation during heating up and cooling, using reaction rate constants determined previously. To estimate inactivation in the 
Table 2. Loss of activity, expressed as a fraction of the initial activity, of the extracellular proteinase from Pseudomonas fluorescens $22 F$ during heating up and cooling periods in the presence and absence of sodium caseinate

\begin{tabular}{|c|c|c|c|c|c|c|}
\hline \multirow[b]{2}{*}{ Temperature, } & \multicolumn{3}{|c|}{ In the presence of $15 \mathrm{~g}$ sodium caseinate/l } & \multicolumn{3}{|c|}{ In the absence of $15 \mathrm{~g}$ sodium caseinate/l } \\
\hline & $\begin{array}{l}\text { Owing to } \\
\text { autoproteolysis }\end{array}$ & $\begin{array}{l}\text { Owing to thermal } \\
\text { inactivation }\end{array}$ & Total & $\begin{array}{l}\text { Owing to } \\
\text { autoproteolysis }\end{array}$ & $\begin{array}{c}\text { Owing to thermal } \\
\text { inactivation }\end{array}$ & Total \\
\hline 80 & $0 \cdot 007$ & $0 \cdot 006$ & $0 \cdot 013$ & $0 \cdot 007$ & $0 \cdot 047$ & $0 \cdot 054$ \\
\hline 100 & $0 \cdot 031$ & $0 \cdot 004$ & $0 \cdot 035$ & $0 \cdot 030$ & $0 \cdot 031$ & $0 \cdot 061$ \\
\hline 120 & $0 \cdot 118$ & $0 \cdot 003$ & $0 \cdot 121$ & $0 \cdot 116$ & $0 \cdot 023$ & $0 \cdot 139$ \\
\hline
\end{tabular}

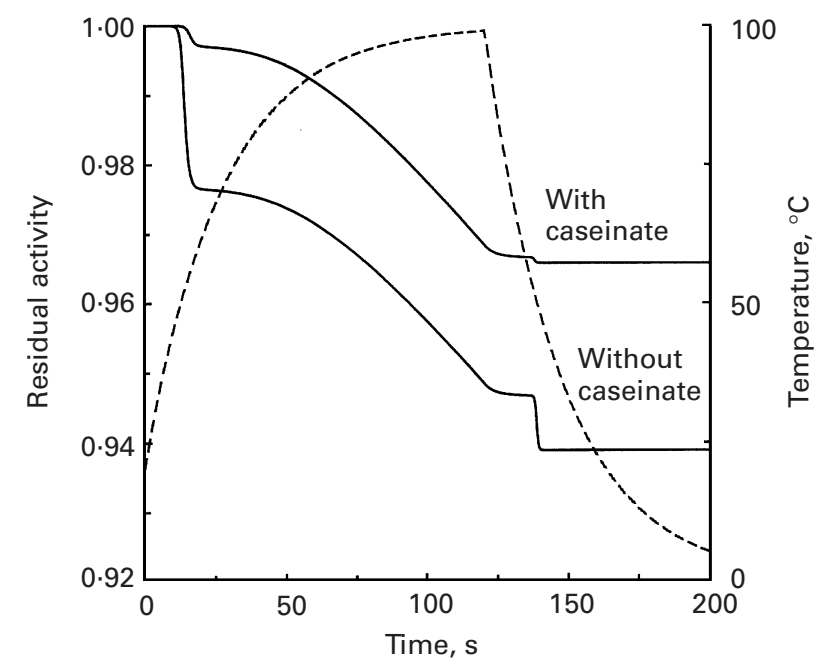

Fig. 1. Calculated inactivation of the proteinase from Pseudomonas fluorescens $22 \mathrm{~F}$ during heating up from 20 to $100{ }^{\circ} \mathrm{C}$ and then cooling to $0{ }^{\circ} \mathrm{C}$ in the presence and absence of $15 \mathrm{~g}$ sodium caseinate/l as a function of time: ——, residual activity; - - - , temperature. Residual activity is expressed as a proportion of the original activity.

temperature range $40-70^{\circ} \mathrm{C}$, reaction rate constants for unfolding, refolding and autoproteolysis at various temperatures were estimated by interpolation from results of Schokker \& van Boekel (1998a). The influence of sodium caseinate on the rate of inactivation by autoproteolysis was calculated as described in Schokker \& van Boekel (1998b), with a Michaelis-Menten constant, $K_{\mathrm{m}}$, of $6 \cdot 7 \times 10^{-5}$ M. For temperatures $>70{ }^{\circ} \mathrm{C}$, we assumed thermal inactivation by a single first order reaction with activation enthalpy, $\Delta H^{\ddagger}$, of $84.5 \mathrm{~kJ} \mathrm{~mol}^{-1}$ and activation entropy, $\Delta S^{\ddagger}$, of $-83 \cdot 2 \mathrm{~J} \mathrm{~mol}^{-1} \mathrm{~K}^{-1}$ (Schokker \& van Boekel, 1997). Inactivation as a function of time was calculated numerically, using a first order Euler forward algorithm with steps of $0.1 \mathrm{~s}$ (Press et al. 1990). The results of the calculations are given in Table 2. As an example, the calculated inactivation during heating to $100{ }^{\circ} \mathrm{C}$ and cooling in the presence and absence of $15 \mathrm{~g}$ sodium caseinate/l is shown graphically in Fig. 1 . It is clear that the contribution of autoproteolysis to the inactivation during the heating up and cooling periods was greater at relatively low heating temperatures and in the absence of sodium caseinate.

Of course, this calculation is a rough approximation of the initial inactivation. Temperature-time profiles of the solution in the tubes were measured at rest, while in the actual experiments the tubes were rotated in the glycerol bath, so that heat 
transfer would have been faster and thermal inactivation more effective. Furthermore, while the reaction rate constants for unfolding, refolding and autoproteolysis from Schokker \& van Boekel (1998a) may be useful to describe their inactivation experiments, they could not accurately describe the unfolding equilibrium. The temperature dependence of the unfolding equilibrium would be expected to be less than calculated (Schokker \& van Boekel, 1998a), so that inactivation by autoproteolysis was underestimated in these calculations. Finally, the reaction rate constants used were derived for the inactivation of an unpurified enzyme preparation of supernatant from a skim milk culture diluted in demineralized water (Schokker \& van Boekel, 1997, 1998 a). However, the experiments described in Schokker \& van Boekel $(1999 b)$ used supernatant from a culture in tryptone-lactose diluted in Tris-maleate, or a purified enzyme preparation. Besides having a different $\mathrm{Ca}^{2+}$ activity and ionic strength, the enzyme preparation used in Schokker and van Boekel $(1997,1999 b)$ also had a slightly higher protein content than the enzyme preparations used in these experiments. As the presence of other proteins reduces the rate of autoproteolysis, the extent of inactivation is underestimated in our calculations, especially for the purified enzyme. Nonetheless, this approximation indicates that autoproteolysis and thermal inactivation cannot completely explain the loss of proteolytic activity during the first $2 \mathrm{~min}$, especially when purified proteinase is used or EDTA is added to the enzyme solution. Hence other, as yet unknown, mechanisms must also play a role in the strong initial inactivation.

Kinetic modelling can be a powerful tool to explain enzyme inactivation results. In this communication we have shown with computer simulations that inactivation of the proteinase from $P s$. fluorescens $22 \mathrm{~F}$ during heating up and cooling could not be ascribed completely to autoproteolysis. Moreover, kinetic modelling allows rigorous checking of proposed reaction schemes. Similar simulations (Schokker, 1997) have been used to explain the shape and position of autoproteolysis curves of the proteinase (Schokker \& van Boekel, 1998a,b).

\section{REFERENCES}

Azcona, J. I., Martín, R., Asensio, M. A., Hernández, P. E. \& Sanz, B. 1988 Heat stable proteinase from Pseudomonas fluorescens AH-70: purification by affinity chromatography on cyclopeptide antibiotics. Journal of Dairy Research 55 217-226

Barach, J. T \& Adams, D. M. 1977 Thermostability at ultrahigh temperatures of thermolysin and a protease from a psychrotrophic Pseudomonas. Biochimica et Biophysica Acta $\mathbf{4 8 5}$ 417-423

Barach, J. T., Adams, D. M. \& Speck, M. L. 1976 Low temperature inactivation in milk of heat-resistant proteases from psychrotrophic bacteria. Journal of Dairy Science 59 391-395

Barach, J. T., Adams, D. M. \& Speck, M. L. 1978 Mechanism of low temperature inactivation of a heatresistant bacterial protease in milk. Journal of Dairy Science 61 523-528

Diermayr, I. P., Kroll, S. \& Klostermeyer, H. 1987 Mechanisms of heat inactivation of a proteinase from Pseudomonas fluorescens biotype I. Journal of Dairy Research 54 51-60

FAtrbatRn, D. J. \& LAW, B. A. 1986 Purification and characterization of an extracellular proteinase from Pseudomonas fluorescens NCDO 2085. Journal of Dairy Research 53 457-466

Fassina, G., Vita, C., Dalzoppo, D., Zamai, M., Zambonin, M. \& Fontana, A. 1986 Autolysis of thermolysin: isolation and characterization of a folded three-fragment complex. European Journal of Biochemistry $\mathbf{1 5 6}$ $221-228$

Fontana, A. 1988 Structure and stability of thermophilic enzymes. Studies on thermolysin. Biophysical Chemistry 29 181-193

Hiddink, J. 1975 Natural Convection Heating of Liquids, with Reference to Sterilization of Canned Foods. PhD thesis, Wageningen Agricultural University

Kroll, S. \& Klostermeyer, H. 1984 Heat inactivation of exogenous proteinases from Pseudomonas fluorescens. I. Possibility of inactivation in milk. Zeitschrift für Lebensmittel-Untersuchung und-Forschung 179 $288-295$

Mrhalyi, E. 1972 Application of Proteolytic Enzymes to Enzyme Structure Studies. Cleveland, OH: CRC Press

Patel, T. R., Bartlet, F. M. \& Haмid, J. 1983 Extracellular heat-resistant protease of psychrotrophic pseudomonads. Journal of Food Protection 46 90-94 
Press, W. H., Flannery, B. P., Teukolsky, S. A. \& Vetterling, W. T. 1990 Numerical Recipes In Pascal: the Art of Scientific Computing. New York: Cambridge University Press

Richardson, B. C. 1981 The purification and characterization of a heat-stable protease from Pseudomonas fluorescens B52. New Zealand Journal of Dairy Science and Technology 16 195-207

SсHокKеR, E. P. 1997 Kinetic Modelling of Enzyme Inactivation. Kinetics of Heat Inactivation of the Extracellular Proteinase from Pseudomonas fluorescens 22F. PhD thesis, Wageningen Agricultural University

SсноккеR, E. P. \& van Boekel, M. A. J. S. 1997 Kinetic modelling of enzyme inactivation: kinetics of heat inactivation at $90-110^{\circ} \mathrm{C}$ of extracellular proteinase from Pseudomonas fluorescens 22F. Journal of Agricultural and Food Chemistry 45 4740-4747

Schokker, E. P. \& van Boekel, M. A. J. S. 1998 a Mechanism and kinetics of inactivation at $40-70{ }^{\circ} \mathrm{C}$ of the extracellular proteinase from Pseudomonas fluorescens 22F. Journal of Dairy Research 65 261-272

Schokker, E. P. \& van Boekel, M. A. J. S. $1998 b$ Effect of protein content on low temperature inactivation of the extracellular proteinase from Pseudomonas fluorescens 22F. Journal of Dairy Research 65 347-352

Schokker, E. P. \& van Boekel, M. A. J. S. 1999 a Effect of $\mathrm{Ca}^{2+}$ and $\mathrm{Zn}^{2+}$ ions on inactivation between 30 and $70^{\circ} \mathrm{C}$ of the extracellular proteinase from Pseudomonas fluorescens $22 \mathrm{~F}$. Milchwissenschaft In press

Schokker, E. P. \& van Boekel, M. A. J. S. $1999 b$ Kinetics of thermal inactivation of the extracellular proteinase from Pseudomonas fluorescens $22 \mathrm{~F}$ : influence of $\mathrm{pH}$, calcium and protein. Journal of Agricultural and Food Chemistry 47 1681-1686

Stepaniak, L. \& Fox, P. F. 1983 Thermal stability of an extracellular proteinase from Pseudomonas fluorescens AFT 36. Journal of Dairy Research 50 171-184

Vita, C., Dalzoppo, D. \& Fontana, A. 1985 Limited proteolysis of thermolysin by subtilisin: isolation and characterization of a partially active enzyme derivative. Biochemistry 24 1798-1806

Yan, L., Langlois, B. E., O'Leary, J. \& Hicks, C. L. 1985 Purification and characterization of four extracellular proteases isolated from raw milk psychrotrophs. Journal of Dairy Science 68 1323-1336 